\title{
Dış Göç Olgusunun Düzensiz Göç Gerçeği: Karşılaşılan Etkilere Ekonomik ve Sosyolojik Çözüm Önerileri ${ }^{1}$
}

Selma Aybüke ŞANLIÖZ, Department of Economics, Faculty of Economics and Administrative Sciences, Dokuz Eylul University, Turkey; e-mail: sanliozaybuke@gmail.com

\section{Irregular Migration Fact of External Migration: Economical and Sociological Solutions to the Problems Encountered ${ }^{2}$}

\begin{abstract}
External migration brings along certain difficulties and problems for both the immigrant country and the immigrant. Turkey became a country that has been receiving increasingly more immigrants in recent years. Certain problems have emerged during these times of excessive external migration. This essay seeks solutions to these problems rather than focusing on the reasons. These suggestions have been examined and conveyed in both economical and sociological sense. Therefore; social community, which is a complementary to economic structure, hasn't been ruled out and mutual development has been mentioned.
\end{abstract}

Keywords $\quad$ : Irregular Migration, Economical and Sociological Impact, Cultural Integration.

JEL Classification Codes : A140, Z100, Z130.

\section{$\ddot{\mathbf{O z}}$}

Dış göç, gerek göç edilen toplum gerekse göç eden kişi açısından birtakım zorlukları ve sorunları beraberinde getirmektedir. Türkiye son yıllarda giderek artan bir göç alan ülke konumuna gelmiştir. Dış göçün yoğun yaşandığı bu dönemlerde bazı sorunlar ortaya çıkmıştır. Bu makalede bu sorunlar üzerinde durulmuş nedenlerinin incelenmesinden ziyade bu sorunlara çözüm önerileri aranmıştır. $\mathrm{Bu}$ öneriler hem ekonomik hem de sosyolojik boyutta irdelenmiş ve aktarılmıştır. Dolayısıyla ekonomik yapının tamamlayıcısı olan sosyal toplum göz ardı edilmemiş ve karşılıklı iyileştirme konu edilmiştir.

1 Bu makale, Dokuz Eylül Üniversitesi İktisadi ve İdari Bilimler Fakültesi İktisat Bölümü tarafindan düzenlenen "Prof.Dr. Mehmet Sadık ACAR Bilimsel Araştırma ve Lisansüstü Tez Yarışması-2016” kapsamında ikincilik ödülüne laylk görülmüştür.

2 This paper had won the "Second Place" in "Prof.Dr. Mehmet Sadlk ACAR Scientific Research and Thesis Competition-2016" organized by Dokuz Eylul University, Faculty of Economics and Administrative Sciences, Department of Economics. 


\section{Giriş ve Kavramlar}

T.C. İçişleri Bakanlığı Göç İdaresi Genel Müdürlüğü’nün yaptığı tanıma göre göç; dini, iktisadi, sosyal ve diğer sebeplerden dolayı insan topluluklarının hayatlarının tamamını veya bir bölümünü geçirmek üzere yaşamlarını sürdürdükleri bir yerden başka bir yere yerleşmek suretiyle yaptıkları coğrafi yer değiştirme hareketidir (İçişleri Bakanlığı Göç İdaresi Genel Müdürlüğ̈̈, $\quad<$ http://www.goc.gov.tr/icerik3/kurumsalkimlik_308_313_315>, 27.04.2016).

Göç, tarih boyunca insanoğlunun dinamik varlığı ve sonsuz talep ve ihtiyaçlarının tetikleyici güdümünde ortaya çıkan sosyal bir hakikattir. Bu hakikat, insan hareketliliğinin en doğal sonucu olarak karşımıza çıkmaktadır (İçişleri Bakanlığı Göç İdaresi Genel Müdürlüğü, <www.goc.gov.tr/icerik>, 26.05.2016). Göçü, nedenleri (zorunlu ve gönüllü göç), amaçları (çalışma, sığınma) ve hedefe varmakta kullanılan yöntemleri (yasal, yasa dışı) gibi farklı kriterlere uygun olarak tanımlamak mümkündür.

Zorunlu göç; savaş, tabi afet, sürgün gibi nedenlerle insanların yaşadıkları yerden ayrı kalmak zorunda olmaları veya buna mecbur bırakılmaları sebebiyle oluşan göçtür. Bireylerin göç etmeye kendilerinin karar verdiği gönüllü göçte ise esas dürtü insanların daha iyi yaşam şartları elde edeceklerini ummalarıdır (Yılmaz, 2014: 1687).

Sığınma talep eden kişiler "1951 tarihli sözleşmede ve diğer evrensel ve bölgesel İnsan Hakları Sözleşmelerinde belirtilen nedenlerle koruma isteyen fakat yetkili bir makam tarafından mültecilik statüsüne uygunluğu henüz tespit edilmemiş kişiler" olarak tanımlanmaktadır (BMMYK, 2010: 8). Aynı sözleşmeye göre "1rkı, dini, tabiiyeti, belli bir toplumsal gruba mensubiyeti veya siyasi düşünceleri yüzünden, zulme uğrayacağından haklı sebeplerle korktuğu için vatandaşı olduğu ülkenin dışında bulunan ve bu ülkenin korumasından yararlanamayan, ya da söz konusu korku nedeniyle, yararlanmak istemeyen veya bir tabiiyeti olmayıp bu tür olaylar sonucu önceden yaşadığı ikamet ülkesinin dışında bulunan, oraya dönemeyen veya söz konusu korku nedeniyle dönmek istemeyen her şahıs" mülteci olarak tanımlanır (BM, 1951 Mültecilerin Hukuki Statüsüne İlişkin Sözleşme, Madde: 1).

Göçmen kendi ülkesinden ayrılırken ve/veya yolu üzerinde bulunan ülkeden geçerken ve/veya göç etmeyi tasarladığ 1 ülkeye girişinde ve/veya bu ülke(ler)de bulunduğu süre içinde o ülkenin yasalarına uyup uymama durumuna göre, yasal ya da yasa dışı olarak da tanımlanabilmektedir. Diğer taraftan günümüzde oldukça yaygın olmakla birlikte, ne zaman hangi yönde olacağ 1 kestirilemeyen, göç eden kitlenin sosyal, demografik ve ekonomik özelliklerinin çok çabuk değişebildiği transit, mekik ve sığınmacı göçlerini kapsayan göçe "düzensiz/düzenlenmemiş” göç adı verilmektedir (Yılmaz, 2014: 1688).

$\mathrm{Bu}$ çalışmada dünyada stratejik önemi giderek artan mülteciler ele alınmış ve bu mülteci olgusunun Türkiye üzerine etkilerinin ekonomik ve sosyolojik boyutu ele alınmıştır. Son zamanlarda özellikle Suriye'deki silahlı iç çatışmadan kaçan ve Türkiye üzerinden 
geçerek Avrupa'ya ulaşmayı hedefleyen mültecilerin Avrupa Birliğinin 'Yasadışı Göçle Mücadele ve Güvenlik' anlayışı kapsamında Geri Kabul Anlaşmalarının yapılması veya uydu kentler belirleme/geri gönderme merkezleri oluşturulmaya çalışılması Türkiye’de mülteci sayısını giderek arttırmıştır.

\section{Şekil: 1}

\section{Yıllara Göre Düzensiz Göçmen Sayısı}

\section{Yllara Göre Düzensiz Göçmen Sayısı}

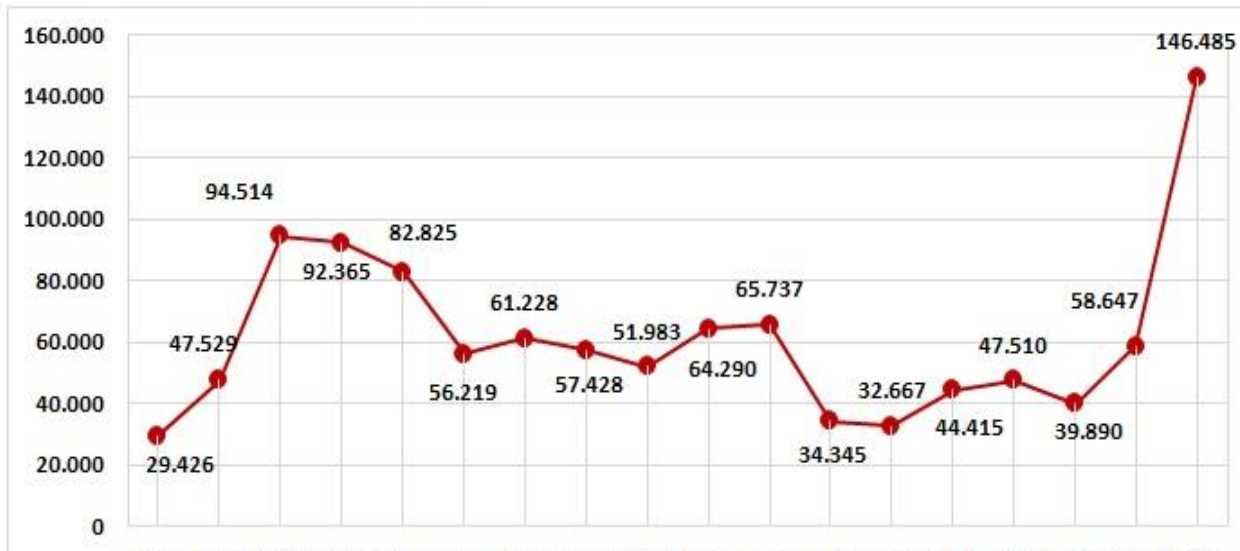

199819992000200120022003200420052006200720082009201020112012201320142015

Kaynak: <http://www.goc.gov.tr/icerik6/duzensiz-goc 3633784710 icerik>, 06.05.2016.

Yukarıda görüldüğü üzere yıllara göre düzensiz göçmen sayısı rakamlarla net bir şekilde ifade edilmiş ve özellikle 2015 yılında en yüksek seviyeye ulaştığı görülmektedir. 2015 yılındaki bu artışın sebebini Suriye'deki silahlı iç çatışma sonucu gelen mültecilerden kaynaklandığı söylenebilir. Fakat Türkiye'de Suriyeli göçmenin yanı sıra farklı milletlerden de göçmen bulunmaktadır. 
Şekil: 2

2015 Yılında Yakalanan Düzensiz Göçmenler İlk 10 Uyruk

2015 Yulında Yakalanan Düzensiz Göçmenler (İlk 10 Uyruk)

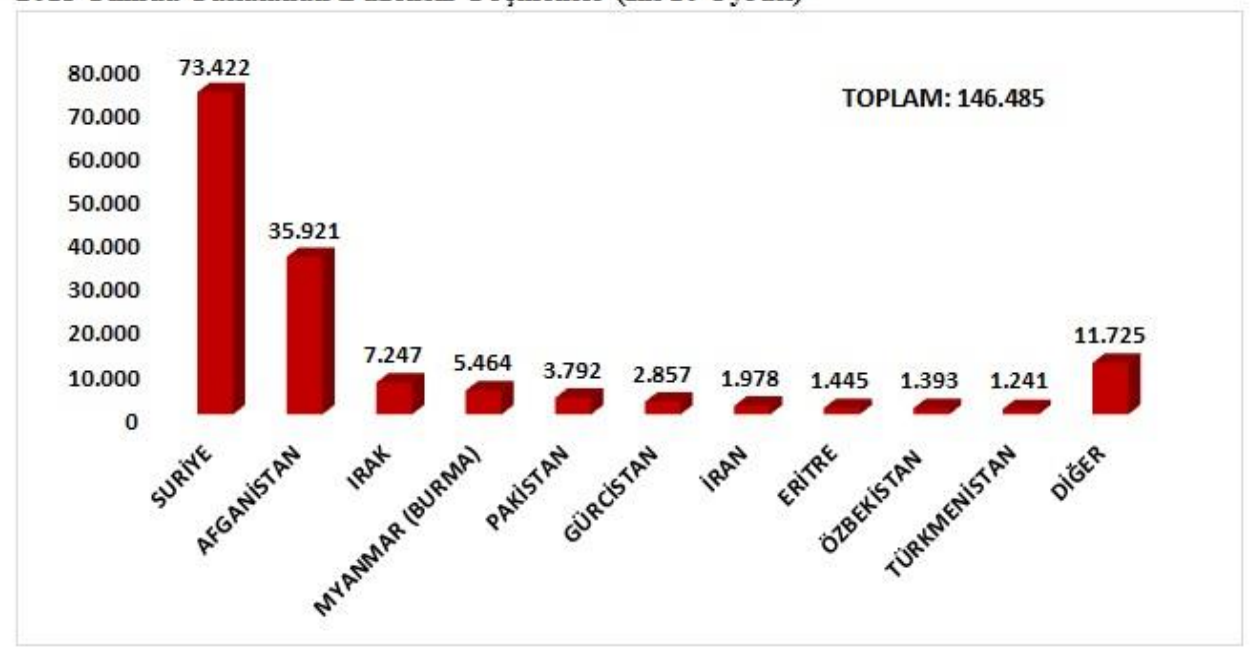

BiRikim 29.426 76.955 171.469 263.834 346.659 402.878 464.106 521.534 573.517 637.807 703.544 737.889 770.556 814.971 862.481 902.371 961.018 1.107.503 Kaynak: <http://www.goc.gov.tr/icerik6/duzensiz-goc_363_378_4710_icerik>,06/05/2016.

Yukarıdaki tabloda düzensiz göç sonucu yakalanan göçmenlerin yüksek oranla Suriye Afganistan ve Irak’tan geldiği görülmektedir.

\section{Mültecilerin Türkiye Üzerine Ekonomik ve Sosyolojik Etkileri}

Çok fazla sayıda insanın vatanı dışında hiç bilmediği bir ülkede ve o ülkenin toplumuyla hayatına devam etmeye çalışması hem göç eden hem de göç alan toplum açısından önemli bir sorun haline gelmiştir. Zira bu sorun günümüzde küresel boyutlara ulaşmış gerek ekonomik gerekse sosyolojik anlamda birtakım etkiler meydana getirmiştir.

\subsection{Ekonomik Etkiler}

Düzensiz göç ile ülkemize gelen göçmenlerin Türkiye ekonomisi üzerine risk ve firsatların iç içe geçtiği şekilde bir etkide bulunduğu söylenebilir.

- Mültecilerin yarattığı etkiyle talep artışı sonucu gerçekleşen kiralarda artışlar kiracı üzerinde olumsuz bir etki yaratırken ev sahibi için bir firsat olmuştur

- Nüfus artışına bağlı olarak kişi başına düşen milli gelirin azalış göstermesi

- Mültecilerin işgücü piyasasına girmesine bağlı olarak işsizliğin artmasının yanı sıra bu kişilerin sanayide, tarımda ve küçük çaplı işletmelerde ucuz işgücü olarak çalıştırılması işini kaybedenlerin sayısını attırması 
- Mültecilere yapılan yardımların bir kısmı yerel işletmelerden temin edilirken bir kısmı ithal edilmektedir. Bu durum özellikle gıda ve tekstil sektöründeki yerel işletmelerin lehine bir tablo çizerken makro-ekonomik anlamda cari işlemler hesabı açık veren bir ülke olan Türkiye'yi olumsuz etkileyecektir.

- Orta ve yüksek gelirli mültecilerin Türkiye'de kendi işletmelerini açmaları büyüme rakamları üzerinde olumlu bir etki yaratmıştır.

\subsection{Sosyolojik Etkiler}

Düzensiz göç ve etkileri olgusu ekonomik etkilerin yanında bir tamamlayıcı etken olan sosyolojik alanda da değerlendirilmelidir. Zira göçün köken ülkedeki çatışmalar dışında, transit ve varılan ülkelerde de gerilimlere ve uzlaşmazlıklara yol açtığ 1 görülmektedir (ERDOĞAN, 2012:298). Bu bağlamda dış göçün toplumsal hayatta birtakım sorunları beraberinde getirdiği söylenebilir.

- Öncelikle göç eden kişilerin yaşadığı dil öğrenme sorunu toplumda bir iletişim sorunu yaratmakta hem göç eden kişi hem de göç alan ülke toplumu açısından zorlu bir süreç olmaktadır.

- Göçmenler göç ettikleri ülkenin onlara sahip oldukları statü bağlamında hangi hakları tanıdığını ve bu haklardan nasıl faydalanabileceğini bilmemektedir.

- Son günlerde önemli bir sorun haline gelen göçmen kişilerdeki salgın hastalıklar hem toplumumuz hem de göçmen kişilerce güç bir durum yaratmaktadır.

- Göçmen kişiler göç ettikleri toplumun kültürel yapısına ayak uyduramamakta var olan toplumsal normlara uyum sağlayamamaktadır. Bu durum göçmen kişi tarafından durumu daha da zorlaştırırken toplumsal yapıda huzursuzluk ve uyumsuzluk yaratarak sosyolojik anlamda önemli bir sorun yaratmaktadır.

\section{Türkiye’de Yaşanan Ekonomik ve Sosyolojik Etkilere Çözüm Önerileri}

Çalışmanın bu bölümünde kendi yazmış olduğum proje olan şuanda koordinatörlüğünü üstlendiğim ve Akdeniz İş Kadınları Derneğinde sunulan sonucunda beş ülkeyle birlikte hayata geçirilmesi hedeflenen 'Mülteci veya Geçici Koruma Altındaki Yabancılara Destek Projesi’ kapsamında geliştirdiğim çözüm önerileri daha geniş kapsamlı ele alınacaktır (Şanlıöz, 2016: 5-8).

Türk toplumu çok kültürlü bir yapıya sahiptir. Bu olgu gerek ekonomik gerek sosyolojik hayatta farklı konularda karşımıza çıkmaktadır. Ayrıca ülkemize göç eden farklı milletlerden insanlar bu olguyla gerek ekonomik anlamda iş bulma sürecinde gerekse sosyolojik anlamda topluma entegre olma konusunda sorun yaşamaktadırlar. Bu bağlamda geliştirilecek çözüm önerilerinin ise gerçekleştirilebilirliği yüksek olmalıdır. Zira küresel boyutta bir etki olan dış göç olgusu yalnız Türkiye'nin değil farklı ülkelerin de sorunu haline gelmiştir.

Ayrıca şuan ülkemizde düzensiz göç sonucu var olan göçmenler devlet politikaları ve kararları açısından topluma entegre edilmeye çalışmaktadır. Dolayısıyla bu konuda 
mevcut durumun sebeplerinin yanında çözüm önerilerinin daha önemli hale geldiği görülmektedir. Biran önce karşılıklı iyileştirmeye gidilmesi daha yararlı olacaktır.

Dolayısıyla bu konuda yapılabilecek bazı çözüm önerileri şunlardır:

- Türkiye emek-yoğun yapıya sahip bir ülkedir. Ayrıca nüfus artış hızının yüksek olmasına karşın bazı sektörlerde yeterli istihdamın sağlanamaması Türkiye'nin olması gerekenden daha az üretim yapmasına ve dolayısıyla Gayri Safi Milli Hasılanın olması gerekenden daha düşük seviyelerde olmasına sebep olmaktadır. İltica sonucu ülkemize sığınmak zorunda kalan göçmenlerin bu sektörlerde çalışmaya teşvik edilmesi ekonomik anlamda karşılıklı fayda sağlayacak aynı zamanda göçmenlerin topluma uyum sürecini hızlandıracaktır.

- Türkiye'de meslek liselerinin giderek azalması buna bağlı olarak teknik eleman açığının artması önemli bir işsizlik sorunu yaratmıştır. Bu konuda gelen göçmenlere bir takım mesleki eğitimlerin verilmesi ve sonrasında ara eleman olarak istihdam edilmesi ekonomiye olumlu etkide bulunacaktır.

- Göç veya iltica sonucu yeni hayatına adapte olmaya çalışan kişilere dil ve iletişim, sağlık ve şehir yaşamı hakkında bilgi verilmesi amacıyla gönüllülük esasına dayalı aktiviteler gerçekleştirilmesi kültürel adaptasyon sürecini hızlandıracaktır. Bu konuda;

- Türkçe dil eğitimleri,

- Koruyucu sağlık eğitimleri (genel sağlık, ağız-diş sağlığı, cinsel korunma yollar1),

- Göç edilen şehrin kültürel yapısı ve normları hakkında eğitimler verilmesi ve bütün bu eğitimlerin gönüllülük esasına dayalı olması ayrıca bu konuda sosyal sorumluluk projeleri gerçekleştiren kurumlara ulaşılması sosyolojik anlamda iyileşme sağlayacaktır (Şanlıöz, 2016: 6).

Yukarıda bahsedilen çözüm önerileri ekonomik ve sosyolojik yaşamı kapsamaktadır. $\mathrm{Bu}$ öneriler doğrultusunda Türkiye'de yaşanan diş göç olgusunun getirdiği sorunlar en aza indirgenmeye çalışılmıştır.

\section{Sonuç}

Türkiye'de yaşanan diş göçe bağlı sorunlar gittikçe önem arz eden bir konu haline gelmiştir. Gelişmekte olan bir ülke yapısına sahip Türkiye'de dış göçün hızlı artışı sonucu bazı sorunlar yaşanmıştır. $\mathrm{Bu}$ makalede bu sorunlar incelenmiş ve çözüm önerileri aranmıştır. Sonuç olarak, ülkemizde var olan göçmen nüfus topluma ekonomik ve sosyolojik anlamda entegre edilmeye çalışılmıştır. Bu çözüm önerilerin gerçekleştirilebilir olmasına önem verilmiş ve hem göç edilen toplum hem de göç eden toplum açısından karşılıklı bir iyileşmeye gidilmiştir. 


\section{Kaynaklar}

Birleşmiş Milletler Mülteciler Yüksek Komiserliği, (2010), Mülteci Statüsü Belirlemede Uygulanacak Usuller ve Kriterler Üzerine Elkitabı.

Birleşmiş Milletler Mülteciler Yüksek Komiserliği (1951), Birleşmiş Milletler Mültecilerin Hukuki Statüsüne Illişkin Sözleşme, <http://www.goc.gov.tr/files/files/multec\%C4\%B1ler\%C4\%B1nhukuk\%C4\%B1statusun s\%C4\%B11\%C4\%B1sk\%C4\%B1nsozlesme.pdf>, 26.05.2016.

Erdoğan, M. (2012), “Göç ve Türkiye”, Migration Letters, 9(4), 297-302.

İçişleri Bakanlığ1 Göç İdaresi Genel Müdürlüğ̈̈, <http://www.goc.gov.tr/icerik3/kurumsalkimlik_308_313_315>27.04.2016.

İçişleri Bakanlığı Göç İdaresi Genel Müdürlüğü, Uluslararası Göç: Çeşitleri Nedenleri ve Etkileri, <http://www.goc.gov.tr/icerik/hakkimizda_308_309>27.04.2016.

İçişleri Bakanlığı Göç İdaresi Genel Müdürlüğü, <www.goc.gov.tr/icerik> 26.05.2016.

İçişleri Bakanlığı Göç İdaresi Genel Müdürlüğü, <http://www.goc.gov.tr/icerik6/duzensizgoc_363_378_4710_icerik> 25.06.2016.

Şanlıöz, S.A. (2016), "Mülteciler ve Geçici Koruma Altındaki Yabancılara Destek Projesi”, (İzmir İş Kadınları (IZİKAD) tarafından desteklenen proje 2015 yılı Nisan ayında Akdeniz İş Kadınlarının organizasyonu çerçevesinde Kahire'de sunulmuş ardından ABD Büyükelçiliğinin Proje Çağrısı Kapsamında Kabul Sürecindedir).

Yılmaz, A. (2014), "Uluslararası Göç: Çeşitleri Nedenleri ve Etkileri”, Turkish Studies Türkoloji Araştırmaları Dergisi, 9(2), 1685-1704. 
Şanlıöz, S.A. (2016), “Dış Göç Olgusunun Düzensiz Göç Gerçeği: Karşılaşılan Etkilere Ekonomik ve Sosyolojik Çözüm Önerileri”, Sosyoekonomi, Vol. 24(30), 139-145. 